\title{
Femtosecond laser microstructuring of alumina toughened zirconia for surface functionalization of dental implants
}

\author{
Angela Carvalho ${ }^{\mathrm{a}, \mathrm{b}, \mathrm{c}, *}$, Liliana Grenho ${ }^{\mathrm{d}, \mathrm{e}}$, Maria H. Fernandes ${ }^{\mathrm{d}, \mathrm{e}}$, Albena Daskalova ${ }^{\mathrm{f}}$, \\ Anton Trifonov $^{g}$, Ivan Buchvarov ${ }^{g}$, Fernando J. Monteiro ${ }^{\mathrm{a}, \mathrm{b}, \mathrm{c}}$ \\ a i3S - Instituto de Investigação e Inovação em Saúde, U. Porto, Porto, Portugal \\ ${ }^{\mathrm{b}}$ INEB - Instituto de Engenharia Biomédica, U. Porto, Porto, Portugal \\ ${ }^{\mathrm{c}}$ Faculdade de Engenharia, Departamento de Engenharia Metalúrgica e Materiais, U. Porto, Porto, Portugal \\ ${ }^{\mathrm{d}}$ Laboratory for Bone Metabolism and Regeneration, Faculdade de Medicina Dentaria, U. Porto, Porto, Portugal \\ ${ }^{\mathrm{e}} L A Q V / R E Q U I N T E$, U. Porto, Porto, Portugal \\ f Institute of Electronics, Bulgarian Academy of Sciences, Sofia, Bulgaria \\ ${ }^{g}$ Physics Department, Sofia University "St. Kliment Ohridski", Sofia, Bulgaria
}

\section{A R T I C L E I N F O}

\section{Keywords:}

Hard ceramics

Alumina toughened zirconia

Dental implants

Femtosecond laser microtexturing

Surface topography

Biological response

\begin{abstract}
A B S T R A C T
The continuous need for high-performance implants that can withstand mechanical loads while promoting implant integration into bone has focused recent research on the surface modification of hard ceramics. Their properties of biocompatibility, high mechanical and fatigue resistance and aesthetic color have contributed to its succefull applications in dentistry. Alumina toughened Zirconia (ATZ) has been gaining attention as a material for dental implants applications due to its advanced mechanical properties and minimal degradation at body temperature. Still, in order to improve tissue response to this bioinert material, additional modifications are desirable. Improving the surface functionality of this ceramic could lead to enhanced implant-tissue interaction and subsequently, a successful implant integration.

In this work, microtopographies were developed on the surface of Alumina toughened Zirconia using an ultrafast laser methodology, aiming at improving the cellular response to this ceramic. Microscale grooves and grid-like geometries were produced on ATZ ceramics by femtosecond laser ablation, with a pulse width of $150 \mathrm{fs}$, wavelength of $800 \mathrm{~nm}$ and repetition rate of $1 \mathrm{kHz}$. The variation of surface topography, roughness, chemistry and wettability with different laser processing parameters was examined.

Cell-surface interactions were evaluated for 7 days on both microstructured surfaces and a non-treated control with pre-osteoblasts, MC3T3-E1 cells. Both surface topographies showed to improve cell response, with increased metabolic activity when compared to the untreated control and modulating cell morphology up to 7 days.

The obtained results suggest that femtosecond laser texturing may be a suitable non-contact methodology for creating tunable micro-scale surface topography on ATZ ceramics to enhance the biological response.
\end{abstract}

\section{Introduction}

The development of load-bearing biomaterials that can withstand high mechanical forces while providing adequate bone integration is still an intensively researched topic. The continuous need for longlasting biomaterials has led several researchers to focus on modern strategies to develop biomaterials based on hard ceramics [1,2].

Hard ceramics have been extensively explored in the field of dentistry and are regularly used as alternatives to Titanium. Disadvantages involving the use of Titanium such as the susceptibility for peri- implantitis, inflammation caused from wear debris, aesthetic problems and cases of poor osteointegration have favored the use of these materials in dental replacements [3-6].

In the recent years, the manufacturing techniques of ceramic materials have advanced significatively, improving the development of high-performance ceramics. Alumina and Zirconia are attractive materials for applications in dental implants and other load-bearing applications where high mechanical resistance is required. This class of bioceramics is characterized by excellent biocompatibility, mechanical and tribological properties $[7,8]$.

\footnotetext{
* Corresponding author. Rua Alfredo Allen 208, 4200-135, Porto, Portugal.

E-mail address: angela.carvalho@ineb.up.pt (A. Carvalho).
} 
Most recently, Alumina toughened Zirconia (ATZ) has been introduced as a ceramic composite that can combine the main advantages of the single-phase ceramics. It shows improved mechanical properties when compared to the monolithic ceramics, with increased fracture toughness, wear resistance and lower hardness, thus being a ceramic that is more easily machined into a final shape [9-11]. Though, since ATZ is a bioinert ceramic it requires surface modifications to enhance its biological performance.

Surface properties such as topography, surface charge and roughness influence the protein adsorption and cellular adhesion to biomaterials surfaces, important initial steps that can contribute to subsequent longer-term stability of the implant.

Topographical surface modifications have shown to influence the response of several cell types, by modulating cell adhesion, morphology, migration and proliferation as well as improving the osteogenic differentiation of mesenchymal stem cells, leading to improved osteointegration [12-15].

While many methods have been developed over the years for surface modifications of biomaterials, most were established for modifying metals and consequently, have reduced applicability to ceramics. Certain methods like sandblasting or acid etching can cause small defects on the surface of the ceramic and affect their long-term stability $[16,17]$.

Most recently, femtosecond laser is being studied for advanced biomaterials processing, due to its unique characteristics of flexibility, efficient control of surface modification, ultrashort pulses and precise ablation with minimal heat affected zones [18].

A main advantage for the application of this technique on hard ceramics processing is the precise machining with a minimal to nonexistent heat effect to the surrounding areas. The ceramic surface can be tailored at the micrometer's range without affecting the bulk properties of the material.

Ideally, the mechanical properties of the material shouldn't be affected by the laser irradiation. However, very limited data concerning the effect of laser surface texturing on the bulk properties of hard ceramics may be found on the literature.

Femtosecond laser machining has already been proposed as an innovative technique to create topographical features on the surface of ceramics, commonly used in the fields of optical and refractory materials. Some studies have reported the use of femtosecond laser to texture the surface of hard ceramics [19-21], although little work has been conducted on periodic surface structuring, particularly with the intent of implants development, with scarce results available on the biological response to these materials [22-25].

In this work, Alumina toughened Zirconia was microtextured using a femtosecond laser in order to develop two types of microstructures on the ceramic surface: grooves and grids. Materials were characterized prior to and after the laser processing to address possible effects of the laser on the ceramic surface characteristics.

MC3T3-E1 cells were cultured on these materials to assess the biological response and the effects of surface topography on cells attachment, morphology and proliferation.

\section{Materials and methods}

\subsection{Materials preparation}

Samples of Alumina toughened Zirconia were prepared in the shape of discs from an initial powder composed of approximately $80 \%$ of $3 \%$ Yttria-stabilized $\mathrm{ZrO}_{2}$ with $20 \%$ of $\mathrm{Al}_{2} \mathrm{O}_{3}$ (TZ-3Y20AB, TOSOH), using a uniaxial press, at $40 \mathrm{~N}$. After, the discs were pre-sintered at $1100^{\circ} \mathrm{C}$, polished and sintered at $1500{ }^{\circ} \mathrm{C}$ for $2 \mathrm{~h}$.

\subsection{Femtosecond laser processing}

The experiments were carried out using a Ti:sapphire mode-locked

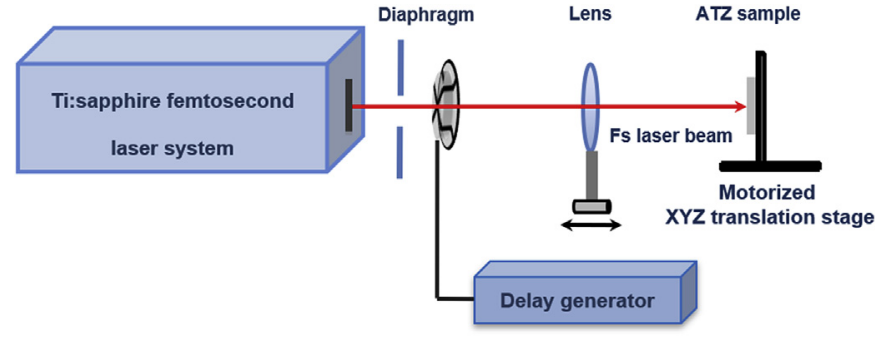

Fig. 1. Experimental setup for femtosecond laser irradiation of ATZ ceramics.

Quantronix - Integra-C system exhibiting pulse duration of $\tau=150 \mathrm{fs}$, at central wavelength of $\lambda=800 \mathrm{~nm}$. The setup for surface texturing was equipped with a XYZ translation stage. The beam profile has a Gaussian shape with $\mathrm{M}^{2}=1.3$. The laser beam was focused trough a lens with focal length of $f=200 \mathrm{~mm}$. The ceramic discs were mounted on the translation stage perpendicularly to the incident laser beam (Fig. 1). The beam waist diameter of $2 \omega_{0}=50 \mu \mathrm{m}$ was determined for the focused laser beam. The focusing lens was positioned on a translation stage equipped with a micrometer screw for fine adjustment of focal position. The obtained laser fluence values were calculated via formula: $\mathrm{F}=2 \times \mathrm{E} / \pi \times \omega_{0}^{2}$, where $\mathrm{E}$ defines pulse energy and $\omega_{0}$ beam radius. The microstructures on the ceramic surface were created via constant scanning the laser beam at a speed of $2 \mathrm{~mm} / \mathrm{s}$, in the $X$ direction to develop the groove patterns and afterwards, in the $\mathrm{Y}$ direction to create the grid patterns. The number of applied laser pulses $(N)$ was controlled with a fast-mechanical shutter which was synchronized with the controlling software.

\subsection{Materials characterization}

\subsubsection{Scanning electron microscopy morphological examination of $f$ s laser patterned ATZ}

Morphological examination of the ceramic's microstructure and the developed microtopographies was conducted by scanning electron microscope. A coupled energy dispersion spectroscope was used for elemental composition analysis (SEM, FEI Quanta 400FEG ESEM/EDAX Genesis X4M).

\subsubsection{Surface roughness}

The surface roughness parameters of the ceramics were evaluated with a profilometer, before and after the laser processing, within an area of $200 \mu \mathrm{m} \times 200 \mu \mathrm{m}$ on each sample (Bruker Dektak stylus profilometer).

Surface roughness profile and nanoroughness parameters of average roughness (Ra), root-mean-square roughness $(\mathrm{Rq})$ and maximum profile peak height $(\mathrm{Rp})$, were obtained for all three materials.

\subsubsection{Diffuse reflectance infrared fourier transformed spectroscopy analysis}

The ceramics were characterized by diffuse reflectance infrared Fourier transformed spectroscopy (DRIFT, Bruker Tensor 27 FTIR spectrometer). Analysis was performed on the laser microstructured surfaces and the control, in the wavelength range of $4000-350 \mathrm{~cm}^{-1}$, with $4 \mathrm{~cm}^{-1}$ steps with 2048 scans accumulated for each spectrum. A baseline correction and smoothing filter were applied to the raw spectra.

\subsubsection{X-ray diffraction phase composition analysis}

X-ray diffraction analysis was performed before and after laser treatment to evaluate the structures of Alumina toughened Zirconia and detect possible phase transformations as a result of the laser processing (Siemens D-500 Kristallofex 710 diffractometer). 

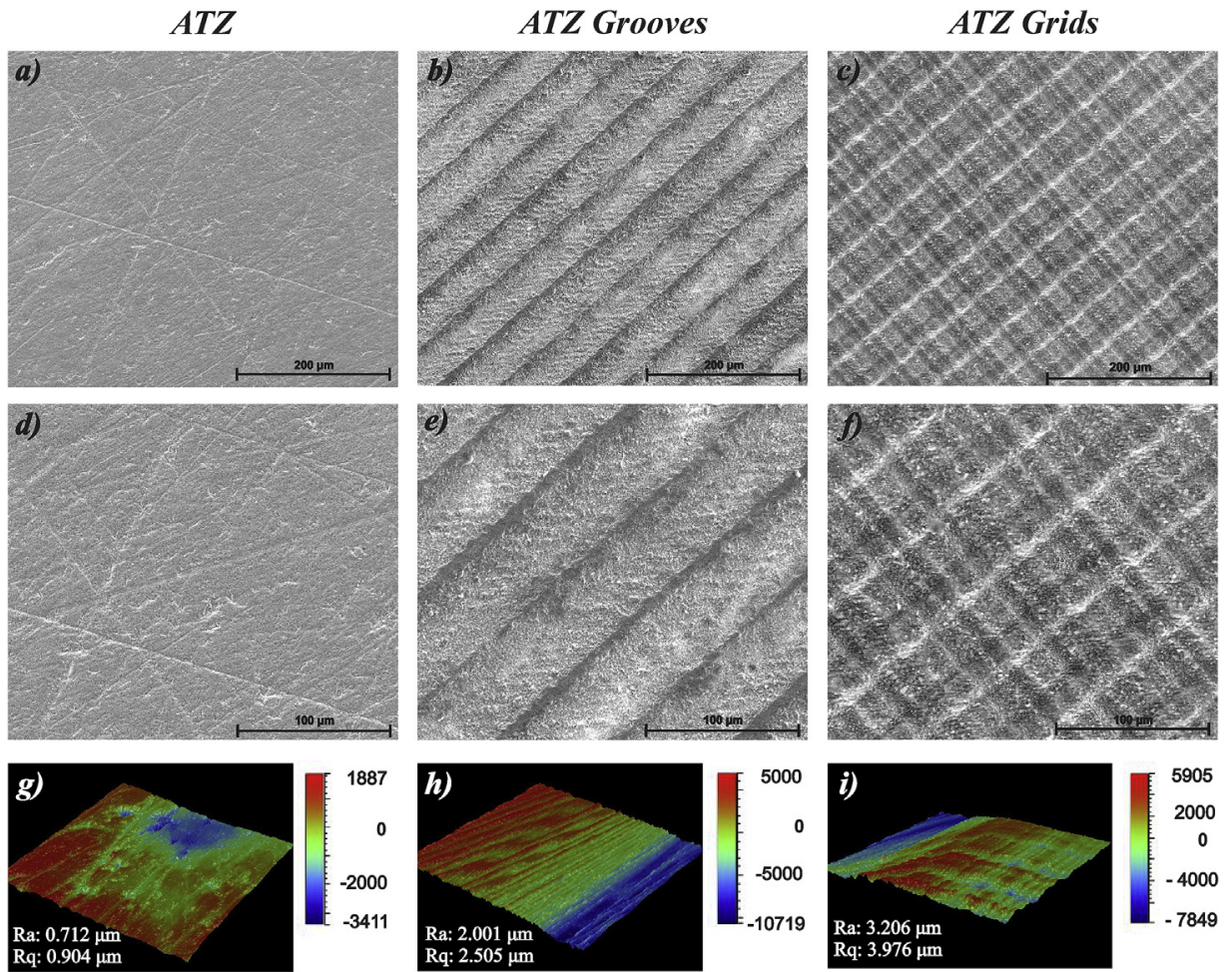

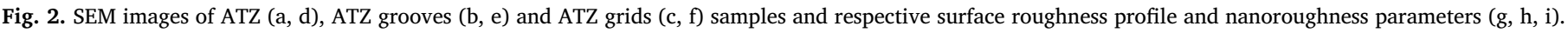
Images $\mathrm{a}, \mathrm{b}$ and $\mathrm{c}$ were obtained at 500x magnification and $\mathrm{d}, \mathrm{e}, \mathrm{f}$ at $1000 \mathrm{x}$ magnification.

\subsubsection{Wettability}

Surface wettability of the materials was assessed by the sessile drop method, with ultrapure water at $25^{\circ} \mathrm{C}$ (OCA 15, Data Physics Instruments $\mathrm{GmbH}$ ). The contact angle was adjusted according to the Laplace-Young equation, using the SCA 20 software, Data Physics Instruments $\mathrm{GmbH}$.

\subsection{Biological characterization}

\subsubsection{Cell culture}

Cell culture experiments were performed to assess and compare the biological response to both laser patterned samples and to the untreated control. MC3T3-E1 cells, an osteoblast precursor cell line, were cultured in alpha minimum essential medium ( $\alpha$-MEM) supplemented with $10 \%$ $(\mathrm{v} / \mathrm{v})$ fetal bovine serum (FBS), $100 \mathrm{U} / \mathrm{mL}$ penicillin, $2.5 \mu \mathrm{g} / \mathrm{mL}$ amphotericin B and $100 \mu \mathrm{g} / \mathrm{mL}$ streptomycin (all reagents from Gibco) in a humidified $5 \% \mathrm{CO}_{2}$ atmosphere at $37^{\circ} \mathrm{C}$.

The materials were sterilized using an autoclave at $120{ }^{\circ} \mathrm{C}$ for $30 \mathrm{~min}$, prior to cell seeding. Subconfluent cells were washed with PBS, trypsinized with $0.05 \%$ trypsin containing $0.25 \%$ EDTA (SigmaAldrich) at $37^{\circ} \mathrm{C}$. MC3T3 cells were seeded on the ceramic substrates and on tissue culture polystyrene (TCPS) for culture control, at density of $2 \times 10^{4}$ cells $/ \mathrm{cm}^{2}$, in a 48 -well plate, and cultured up to 7 days. The cell culture was evaluated throughout the culture time as described below.

\subsubsection{Metabolic activity}

Cells metabolic activity was quantified by the resazurin assay. Cells were incubated with fresh medium with $10 \%$ resazurin for $3 \mathrm{~h}$. After, $100 \mu \mathrm{l}$ were transferred to a 96-well plate and the fluorescence was measured in a microplate reader at $535 \mathrm{~nm}$ and $590 \mathrm{~nm}$ for excitation and emission wavelengths, respectively (Synergy HT, BioTek). The results were expressed in relative fluorescence units (RFU).

\subsubsection{Cell morphology}

Cells morphological evaluations were carried out by scanning electron microscopy and confocal microscopy.

For cells morphological assessment via scanning electron microscopy (FEI Quanta $400 \mathrm{FEG} / \mathrm{ESEM}$ ), samples fixed in 3.7\% paraformaldehyde for $15 \mathrm{~min}$ were dehydrated in graded ethanol solutions (50-100\%) for $10 \mathrm{~min}$ each, followed by critical point drying (CPD 7501, Polaron Range $\ll$ ) and sputter-coated (SPI-Module) with palladium-gold alloy.

For morphology assessment via fluorescence staining, fixed samples (3.7\% paraformaldehyde, $15 \mathrm{~min}$ ) were permeabilized with $0.1 \%(\mathrm{v} / \mathrm{v})$ Triton X-100 (Sigma-Aldrich) for $30 \mathrm{~min}$ followed by $30 \mathrm{~min}$ in $1 \%$ bovine serum albumin (BSA, Sigma-Aldrich) solution, to block nonspecific interactions. F-actin filaments were stained using Alexa Fluor 488-conjugated phalloidin (Invitrogen) for $30 \mathrm{~min}$, at room temperature (RT), and the nuclei were stained with a buffer of Propidium iodide and RNase (BD Pharmigen) for $10 \mathrm{~min}$ at RT. A Spectral Confocal Microscope Leica TCS-SP5 AOBS (Leica) was used to observe cells after staining.

\subsection{Statistical analysis}

All parameters were tested with triplicate experiments. The results were expressed as the arithmetic mean \pm standard deviation. The results were statistically analyzed using the one-way analysis of variance (One-way ANOVA) followed by the Tukey HSD post hoc test. Levels of $p \leq 0.05$ were considered statistically significant. The SPSS statistical software was used to perform the analysis (Statistical Package for the Social Sciences Inc., USA). 


\section{Results}

\subsection{Materials characterization}

\subsubsection{Morphological examination of $f$ s laser patterned ATZ via scanning electron microscopy}

SEM results showed the structure of Alumina toughened Zirconia before and after the femtosecond laser treatments (Fig. 2 a-f).

Femtosecond laser treatments were successfully applied, developing identical grooves and grids on the ceramic surface. The ATZ grooves material exhibited parallel microgrooves over the whole sample surface with a groove's periodicity of about $\sim 40 \mu \mathrm{m}$ (Fig. $2 \mathrm{~b}$, e). The interference of both laser treatments gave rise to the grid microstructures, with the grooves from each laser treatment intersecting perpendicularly (Fig. 2 c, f). No signs of melting, crack formation or heat affected zones (HAZ) were identified on both microstructured materials.

The EDS spectra of all samples were identical and detected the following elements: $\mathrm{Zr}, \mathrm{Al}, \mathrm{O}, \mathrm{C}$, showing that the elemental composition of the surface was not altered by the laser processing.

\subsubsection{Surface roughness}

The surface roughness profiles of the control and the laser microstructured surfaces are shown in Fig. 2 g-i. The roughness parameters evaluated were the average roughness (Ra), the root mean square roughness $(\mathrm{Rq})$ and the maximum profile peak height (Rp). The untreated surface displays a much smoother profile with lower average roughness $(\mathrm{Ra}=0.712 \pm 0.057 \mu \mathrm{m})$, lower values of the root mean square $(\mathrm{Rq}=0.904 \pm 0.099 \mu \mathrm{m})$ and the maximum profile peak height $(\mathrm{Rp})$ at $1.900 \pm 0.456 \mu \mathrm{m}$. In terms of the laser treated surfaces, the roughness measurements revealed a $\mathrm{Ra}=2.001 \pm 0.440 \mu \mathrm{m}$ and $\mathrm{Rq}=2.505 \pm 0.701 \mu \mathrm{m}$ on the ATZ grooves and the higher roughness parameters on the ATZ grids with $\mathrm{Ra}=3.206 \pm 0.737 \mu \mathrm{m}$ and $\mathrm{Rq}=3.976 \pm 1.034 \mu \mathrm{m}$. In terms of the maximum profile peak height (Rp), on the ATZ grooves the value was $5.850 \pm 2.862 \mu \mathrm{m}$ while on the ATZ grids was $6.980 \pm 2.048 \mu \mathrm{m}$. The combinatory approach of laser structuring to develop the grid-like geometry increased the overall Ra, $\mathrm{Rq}$ and $\mathrm{Rp}$ values.

\subsubsection{Diffuse reflectance infrared fourier transformed spectroscopy analysis}

Considering the spectra of the laser microstructured materials and the control, four peaks were identified in the region between $2500 \mathrm{~cm}^{-1}$ to $350 \mathrm{~cm}^{-1}$ (Fig. 3 a). After laser processing, the intensity of all peaks and bands is relatively lower on both spectrums, of ATZ grooves and ATZ grids, when compared to the control sample, ATZ. A slight shift to the right was also observed on the spectrums of both laser treated materials.

The peak at $877 \mathrm{~cm}^{-1}$ refers to the stretching of crystalline $\mathrm{Al}-\mathrm{O}$ bonds, while the low intensity peak found at $755 \mathrm{~cm}^{-1}$ is associated to $\mathrm{Al}-\mathrm{O}$ vibrations and the sharp peak at $631 \mathrm{~cm}^{-1}$ corresponds to the stretching modes of the $\mathrm{AlO}_{6}{ }^{3-}$ octahedral $[26,27]$. Finally, $\mathrm{Zr}-\mathrm{O}$ vibrations were found at the band $510-560 \mathrm{~cm}^{-1}$ [28].

\subsubsection{X-ray diffraction phase composition analysis}

The X-ray diffractograms of all samples are presented in Fig. 3 b). Identical spectrums were obtained for all three materials with the phases of $\alpha$-corundum, tetragonal zirconia and monoclinic zirconia. One peak representing monoclinic Zirconia $\left(\mathrm{Z}_{\mathrm{m}}\right)$ was detected on all samples at $2 \theta=28.5$.

The alumina phase of $\alpha$-corundum was detected at $2 \theta=25.6 ; 35.1$; $37.8 ; 43.4 ; 52.5$ and 57.6 while the tetragonal phase of zirconia $\left(\mathrm{Z}_{\mathrm{t}}\right)$ was present at $2 \theta=30.2 ; 34.6 ; 50.2 ; 50.6$ and 59.3.

\subsubsection{Wettability}

In terms of wettability properties, all surfaces exhibited immediate hydrophobic behavior, with increasing values of hydrophobicity for the microstructured materials when compared to the ATZ control (Fig. 4). In the microstructured materials, as noticed for the surface roughness parameters, the value increased in relation to the type of laser treatment, lower for the ATZ grooves and higher for ATZ grids surface.

\subsection{Biological characterization}

\subsubsection{Metabolic activity}

The metabolic activity of MC3T3 cells during the 7 days of culture is displayed in Fig. 5. Cells metabolic activity was maintained between days 1 and 3, and increased significantly from day 3 to day 7, on all surfaces. Both microstructured surfaces induced a statistically significantly higher cellular metabolic activity at all time-points. No statistically significant differences were found between both microstructured surfaces.

\subsubsection{Cell morphology}

Scanning electron microscopy images show cell adhesion and morphology at the initial time-points of culture (day 1 and day 3, Fig. 6). Cells were well adhered to all the surfaces, with a spread morphology and formation of filopodia. A more random organization and more flattened morphology was noticed on the control, ATZ.

On both microstructured surfaces, cells seem to be modulated by the underlying topography with a more stretched morphology on both the grooves and the grids, also at days 1 and 3. Cells on the grooves stretched across the topographies while the cells on the grids spread to different direction of the microstructures.

At day 7, MC3T3 cells morphology was assessed by confocal microscopy. Proliferation was observed on all surfaces. Cells on the control ceramic continued to show an arbitrary morphological organization and proliferation. On both laser textured surfaces cells continue to be modulated by the microstructures with cells well stretched inside the grooves and spreading to several directions on the grids.

On the ATZ grooves, cell proliferation is more evident than on the control and a forming layer of cells appears more oriented according to the surface topography. On the ATZ grids, the forming layer of cells show to be interconnected with each other, with multidirectional morphology, influenced by the underlying topography.

\section{Discussion}

Surface modification can provide exceptional control over the host tissue response to the implanted biomaterial. In recent years, femtosecond laser technique has been increasingly used to microtexture the surface of several types of biomaterials, due to its high flexibility, precise ablation and practically absent heat effects. The material ablation triggered by femtosecond laser radiation is a complex physicochemical process. It develops firstly with absorption of laser energy, followed by thermal diffusion and initiation of plasma expansion. The femtosecond laser radiation is characterized by short pulse width, thus the absorbed energy diffusion is limited within the time interval of the laser pulse. The ablation develops without thermal effect and heat affected zones (HAZ) due to the very short interaction times on the time scale of a few picoseconds [18].

No thermal alterations or molten zones were observed from the laser processing on the microstructure of both processed surfaces. Additionally, material characterization by EDS, DRIFT and XRD showed that there were no chemical or phase alterations to the composition of the ATZ after laser processing.

On DRIFT analysis, the slightly lower intensity and shift of certain peaks of the laser processed ATZ samples, can evidence changes to the structure organization and a less crystalline surface. This is distinguished by the alteration of the grain on the surface, after laser processing [29].

One peak representing the monoclinic phase of zirconia was detected by XRD on all samples. The appearance of this phase can be, on 
a)

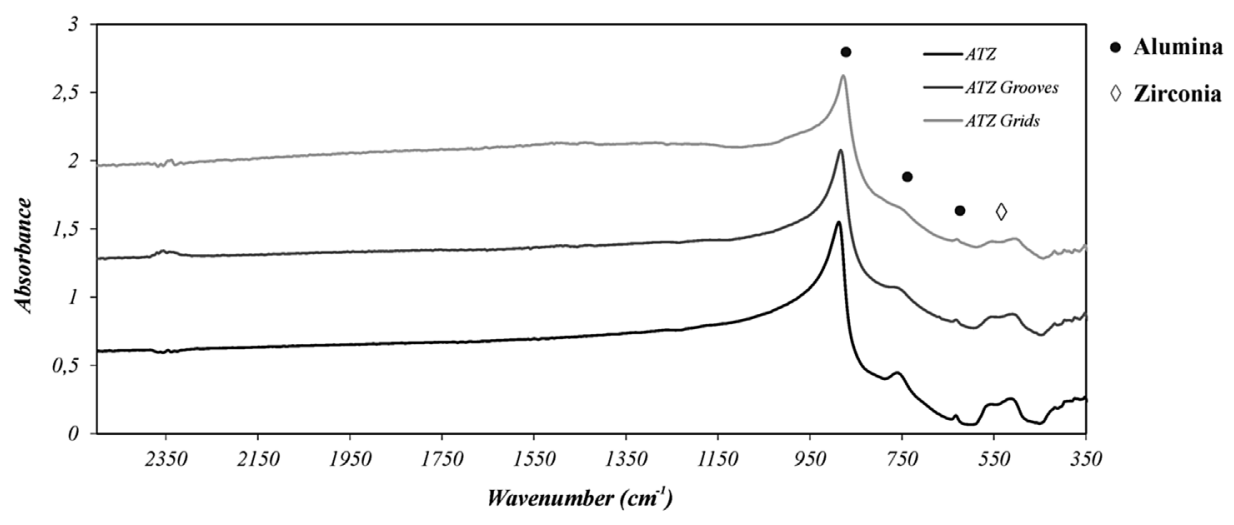

b)

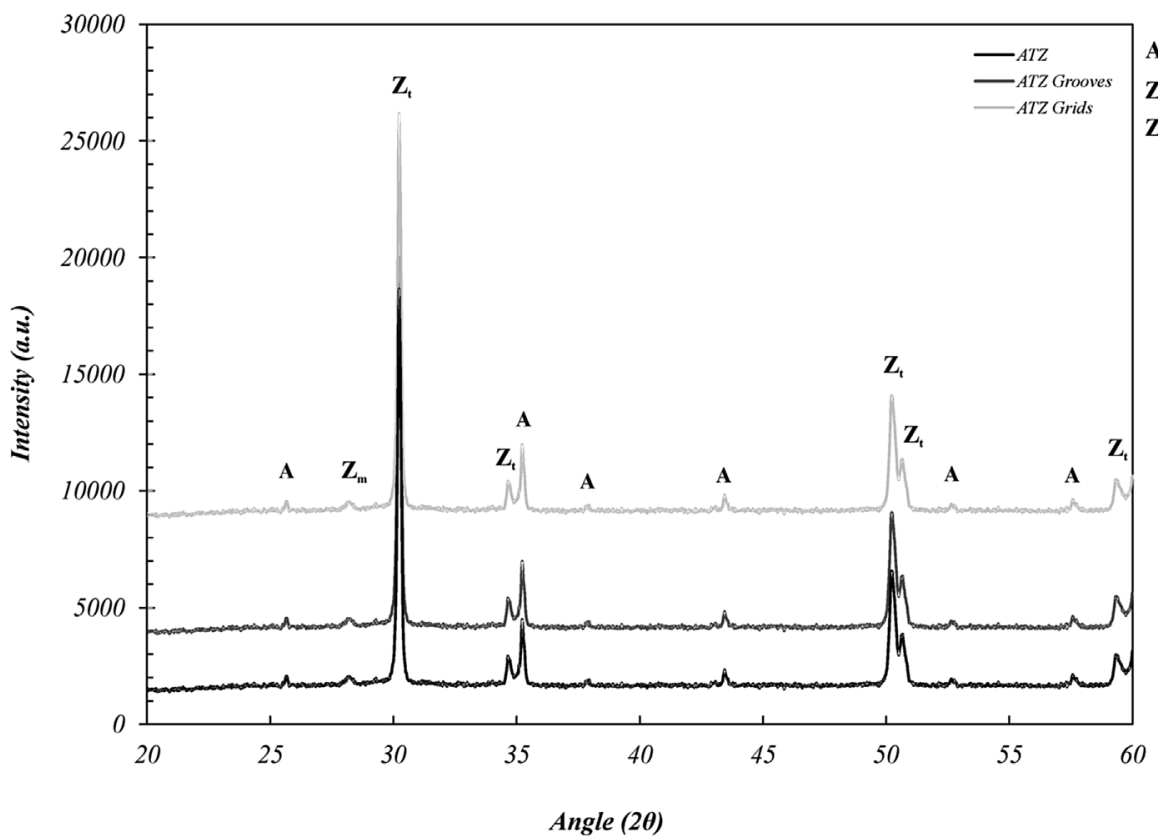

A: $\alpha$ - corundum

$Z_{t}$ : tetragonal zirconia.

$\mathbf{Z}_{\mathrm{m}}$ : monoclinic zirconia

Fig. 3. DRIFT spectra (a) and XRD (b) characterization of the ATZ, ATZ grooves and ATZ grids surfaces. (a) $\bullet$ refers to Alumina and $\diamond$ to Zirconia. (b) $Z_{t}$ refers to the tetragonal phase of Zirconia, $Z_{m}$ to the monoclinic phase of Zirconia and A to the alpha-corundum phase of Alumina.

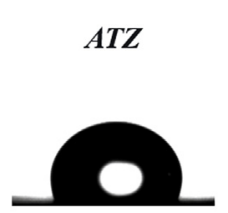

$115,65 \pm 1,20$

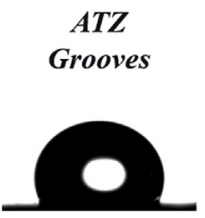

$119,19 \pm 1,84$

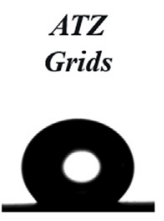

$141,47 \pm 5,30$
Fig. 4. Water contact angle measurements on all three surfaces (ATZ, ATZ grooves and ATZ Grids).

one side, attributed to the sintering of the ceramic at $1500{ }^{\circ} \mathrm{C}$, since the slightly higher temperatures could have led to an augmented grain size and minor transformation from the tetragonal to the monoclinic phase during cooling [30]. Other authors have also reported certain percentages of monoclinic zirconia, detected by XRD, on the green bodies of Alumina toughened Zirconia [31], and after sintering [32]. The same peak for monoclinic zirconia was noticed on all three samples, meaning that the laser treatment didn't cause the appearance of monoclinic zirconia. Aivazi et al. also observed this on their experiments with alumina (20\%vol)-yttrium stabilized tetragonal zirconia poly crystal (A-Y-TZP20). The same fraction of monoclinic zirconia was found on the non-treated and laser treated specimens, concluding that the

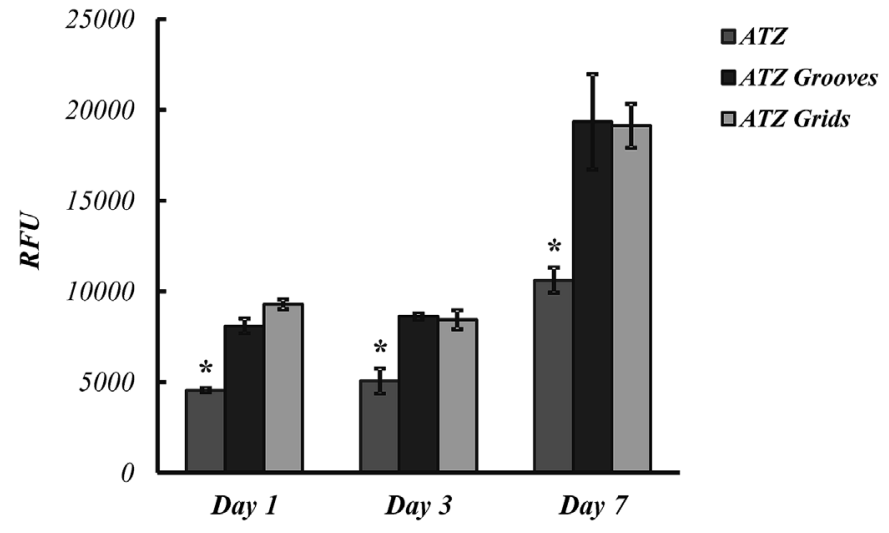

Fig. 5. Cell metabolic activity MC3T3 cells cultured on ATZ, ATZ grooves and ATZ grids. * represents statistically significant differences ( $\leq \leq 0.05$ ) between the three materials, at each time-point.

femtosecond laser did not alter the crystal structure of the ceramic [33].

As expected, the surface roughness increased after the laser microtexturing. The control ATZ displayed a much smother surface, with lower roughness values. Both microstructured materials displayed 

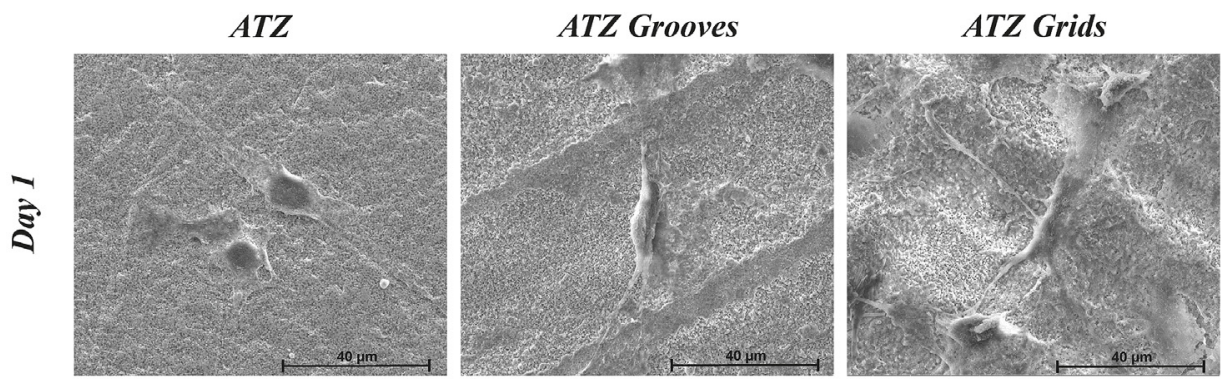

Fig. 6. MC3T3 morphology on the ATZ, ATZ grooves and ATZ grids at day 1 and 3 of culture by SEM and at day 7 by confocal laser scanning microscopy (CLSM). Cells F-actin was stained with phalloidin 488 (green) and nuclei with propidium iodide (red). (For interpretation of the references to color in this figure legend, the reader is referred to the Web version of this article.)
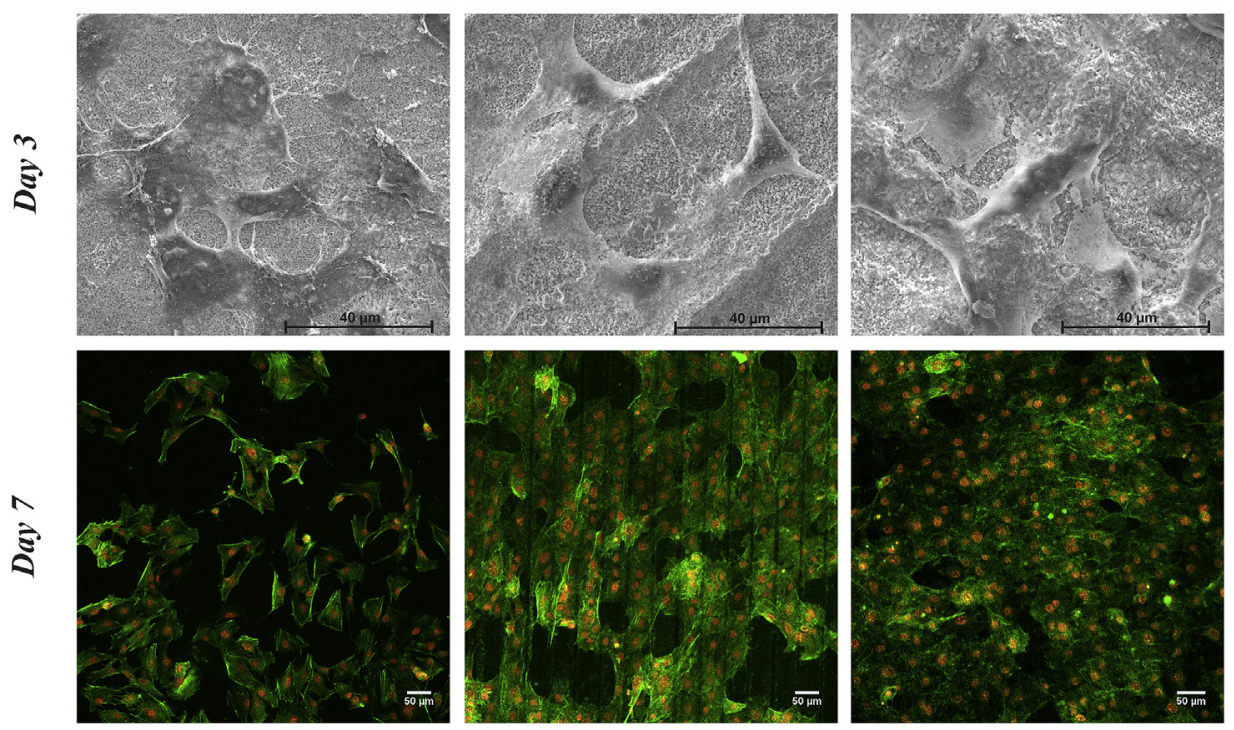

significantly higher values of roughness for all the measured parameters. Thus, the increase in the surface roughness led to an increased hydrophobicity. This was more evident for the ATZ grids, while the ATZ grooves surface displayed only a slightly higher contact angle value when compared to the control surface.

The ATZ grids surface showed the higher values of roughness (Ra and $\mathrm{Rq}$ ), which led to a higher hydrophobicity, as it has been shown that, in surfaces with an initial hydrophobic behavior, the introduction of roughness will enhance the hydrophobicity [34,35].

According to these results, it was determined that the wettability of the laser treated samples was affected by the surface microstructures since the chemistry was shown to be the same as the untreated ATZ.

Both laser treated surfaces showed improved cellular response, meaning that the underlying topography may have strengthened cell adhesion and increased the metabolic activity.

The control over cell-surface interactions has increasingly become the main focus when developing new implants. Surface pattering techniques have allowed for continuous exploration of cell-biomaterial interactions, showing that surface topography plays a substantial role on cellular response to biomaterials [36,37].

Cellular functions such as adhesion, migration and proliferation are deeply affected by physical stimuli from the surrounding microenvironment, though specific cell responses are also dependent on other factors such as cell type, size, the geometric shape of the underlying topography and surface chemistry. Thus, identifying which exact topographies promotes specific responses from specific cell lines has been imperative to improve implant design and performance [38,39].

MC3T3-E1 cells were used in this work to evaluate the effects of different surface topographies on cellular response. Cellular viability increased through culture time, with statistically significant higher values for both microstructured materials. In addition, cells showed to be modulated by the surface topography, which was more evident at day 7 when different cellular morphologies are identified for each substrate, being possible to recognize the underlying topography below the forming layers of cells, on the microstructured surfaces.

As previously mentioned, research is rare on Alumina toughened Zirconia structured by femtosecond laser, even more in terms of biological characterization.

Some authors have performed extensive material characterization on hard ceramics modified by femtosecond laser, aiming at dental implants applications $[21,33,40]$. On Zirconia, Stanciuc et al. developed arrays of pits with different spacing, diameter and depth to evaluate human mesenchymal stem cells migration (hMSCs). Successful fabrication by femtosecond laser was achieved and the pits with $30 \mu \mathrm{m}$ of diameter and $10 \mu \mathrm{m}$ deep could be prone to induce stem cell commitment to the osteoblastic lineage based on the morphological evaluation of the cells [41].

More recently, Goyos-Ball et al. used laser patterning on 10CeTZP$\mathrm{Al} 2 \mathrm{O} 3$ to develop grid-like microstructures with different interspacing and groove depths. Results showed that a grid microstructure with $10 \mu \mathrm{m}$ groove spacing and $1.5 \mu \mathrm{m}$ depth induced increased osteogenic differentiation, when compared to other developed microstructures.

Previously, we reported the use of a femtosecond laser technique on the surface of ATZ, developing microgrooves with overlapping highfrequency LIPSS (laser induced periodic surface structures) that modulated cells adhesion, proliferation and induced increased osteogenic differentiation when compared with the non-treated control [25].

In this work, we proposed a femtosecond laser technique to successfully develop groove and grid-like micrometric patterns on ATZ, without affecting the material properties. Early in vitro assessment showed improved cellular response for both micropatterns with modulation of cell morphology. In future studies, it would be of further interest to assess the potential effects of the laser surface texturing on the ATZ mechanical properties and long-term stability, as well as responses of other cellular types to these laser structured materials, such as the micropatterns geometries effect on the osteogenic differentiation of MSCs, in order to identify specific microstructures that could rapidly promote tissue regeneration and implant osteointegration. 


\section{Conclusions}

In this work, an experimental study was conducted to characterize the fs laser texturing of ATZ ceramics. Two different geometries, groove and grid-like patterns, were prepared without thermal alterations and molten zones. Femtosecond laser processing influenced surface roughness and wettability of ATZ ceramics while the chemical and phase compositions were maintained. Cells cultured on both laser treated surfaces showed increased metabolic activity at all time-points. Cells were modulated by the topography with stretched morphology and oriented growth throughout the 7 days of culture.

The groove and grid-like patterned surfaces were found to promote a directional cell adhesion and increased proliferation towards the developed microtextures with increased cell-cell contact after 7 days, when compared to the non-treated surface. Femtosecond laser processing is an attractive tool to develop micro-features on the surface of hard bioceramics, improving the biological response to these materials and elicit specific responses from cells, dependent of the surface topography. Thus, further exploitation of this method of material processing is significant, particularly for biomedical applications. The development of high-performance ceramics with adequate mechanical characteristics and tailored surface, capable of modulating host-implant interactions, could greatly improve the current available strategies.

\section{Acknowledgments}

This work was supported by FEDER funds through the Programa Operacional Factores de Competitividade (COMPETE) (POCI/01/0145/ FEDER/007265), by Portuguese funds through FCT (Fundação para a Ciência e a Tecnologia) for A. Carvalho grant (SFRH/BD/87624/2012), by the Bulgarian National Science Fund under project No. DN08/5 and by the European Cooperation in Science and Technology under COST Action MP1301 NEWGEN. The authors acknowledge the support of the i3S Scientific Platform Bioimaging, member of the PPBI (PPBI-POCI-010145-FEDER-022122).

\section{References}

[1] O. Roualdes, M.E. Duclos, D. Gutknecht, L. Frappart, J. Chevalier, D.J. Hartmann, In vitro and in vivo evaluation of an alumina-zirconia composite for arthroplasty applications, Biomaterials 31 (2010) 2043-2054.

[2] A.M. Stanciuc, Q. Flamant, K. Biotteau-Deheuvels, M.J. Stoddart, M. Anglada, A.A. Porporati, et al., Human primary osteoblast behaviour on microrough zirconiatoughened alumina and on selectively etched microrough zirconia-toughened alumina, J. Eur. Ceram. Soc. 38 (2018) 927-937.

[3] A. Sicilia, S. Cuesta, G. Coma, I. Arregui, C. Guisasola, E. Ruiz, et al., Titanium allergy in dental implant patients: a clinical study on 1500 consecutive patients, Clin. Oral Implant. Res. 19 (2008) 823-835.

[4] M. Pettersson, J. Pettersson, A. Johansson, M.M. Thoren, Titanium release in periimplantitis, J. Oral Rehabil. 46 (2019) 179-188.

[5] M. Eger, S. Hiram-Bab, T. Liron, N. Sterer, Y. Carmi, D. Kohavi, et al., Mechanism and prevention of titanium particle-induced inflammation and osteolysis, Front. Immunol. 9 (2018).

[6] R.M. Urban, J.J. Jacobs, M.J. Tomlinson, J. Gavrilovic, J. Black, M. Peoc'h, Dissemination of wear particles to the liver, spleen, and abdominal lymph nodes of patients with hip or knee replacement, J Bone Joint Surg Am 82a (2000) 457-477.

[7] P.N. De Aza, A.H. De Aza, S. De Aza, Crystalline bioceramic materials, Bol Soc Esp Ceram V 44 (2005) 135-145.

[8] J. Huang, S. Best, 1 - Ceramic Biomaterials for Tissue Engineering. Tissue Engineering Using Ceramics and Polymers, second ed., Woodhead Publishing, 2014, pp. 3-34.

[9] Y. Yang, Y. Kang, M. Sen, S. Park, Bioceramics in Tissue Engineering. Biomaterials for Tissue Engineering Applications, Springer, 2011, pp. 179-207.

[10] A. Nevarez-Rascon, A. Aguilar-Elguezabal, E. Orrantia, M.H. Bocanegra-Bernal, On the wide range of mechanical properties of ZTA and ATZ based dental ceramic composites by varying the $\mathrm{Al} 2 \mathrm{O} 3$ and $\mathrm{ZrO} 2$ content, Int J Refract Met H 27 (2009) 962-970.

[11] A.H. De Aza, J. Chevalier, G. Fantozzi, M. Schehl, R. Torrecillas, Crack growth resistance of alumina, zirconia and zirconia toughened alumina ceramics for joint prostheses, Biomaterials 23 (2002) 937-945.

[12] L. Le Guehennec, A. Soueidan, P. Layrolle, Y. Amouriq, Surface treatments of titanium dental implants for rapid osseointegration, Dent. Mater. : official publication of the Academy of Dental Materials 23 (2007) 844-854.

[13] R. Junker, A. Dimakis, M. Thoneick, J.A. Jansen, Effects of implant surface coatings and composition on bone integration: a systematic review, Clin. Oral Implant. Res. 20 (Suppl 4) (2009) 185-206.

[14] D. Falconnet, G. Csucs, H.M. Grandin, M. Textor, Surface engineering approaches to micropattern surfaces for cell-based assays, Biomaterials 27 (2006) 3044-3063.

[15] A. Carvalho, A. Pelaez-Vargas, D.J. Hansford, M.H. Fernandes, F.J. Monteiro, Effects of line and pillar array microengineered SiO2 thin films on the osteogenic differentiation of human bone marrow-derived mesenchymal stem cells, Langmuir the ACS journal of surfaces and colloids 32 (2016) 1091-1100.

[16] Y. Zhang, B.R. Lawn, E.D. Rekow, V.P. Thompson, Effect of sandblasting on the long-term performance of dental ceramics, J. Biomed. Mater. Res. B Appl. Biomater 71 (2004) 381-386.

[17] Y. Zhang, B.R. Lawn, K.A. Malament, P. Van Thompson, E.D. Rekow, Damage accumulation and fatigue life of particle-abraded ceramics, Int. J. Prosthod. 19 (2006) $442-448$

[18] K. Sugioka, Y. Cheng, Femtosecond laser three-dimensional micro- and nanofabrication, Appl. Phys. Rev. 1 (2014).

[19] Z.Y. Zhai, W.J. Wang, J. Zhao, X.S. Mei, K.D. Wang, F.C. Wang, et al., Influence of surface morphology on processing of $\mathrm{C} / \mathrm{SiC}$ composites via femtosecond laser, Compos Part a-Appl S 102 (2017) 117-125.

[20] J.P. Cui, Z.Y. Gong, P.G. Rao, Effect of molten zone ablated by femtosecond laser on fracture toughness of oxide ceramics, J. Eur. Ceram. Soc. 38 (2018) 2440-2444.

[21] N. Ackerl, M. Warhanek, J. Gysel, K. Wegener, Ultrashort-pulsed laser machining of dental ceramic implants, J. Eur. Ceram. Soc. 39 (2019) 1635-1641.

[22] V. Garcia-Sanz, V. Paredes-Gallardo, C. Bellot-Arcis, O. Mendoza-Yero, C. DonateBuendia, J. Montero, et al., Effects of femtosecond laser and other surface treatments on the bond strength of metallic and ceramic orthodontic brackets to zirconia, PLoS One 12 (2017).

[23] X.C. Wang, H.Y. Zheng, P.L. Chu, J.L. Tan, K.M. Teh, T. Liu, et al., Femtosecond laser drilling of alumina ceramic substrates, Appl Phys a-Mater. 101 (2010) 271-278.

[24] E.A. Erdur, F.A. Basciftci, Effect of Ti:Sapphire-femtosecond laser on the surface roughness of ceramics, Lasers Surg. Med. 47 (2015) 833-838.

[25] A. Carvalho, L. Cangueiro, V. Oliveira, R. Vilar, M.H. Fernandes, F.J. Monteiro, Femtosecond laser microstructured Alumina toughened Zirconia: a new strategy to improve osteogenic differentiation of hMSCs, Appl. Surf. Sci. 435 (2018) 1237-1245.

[26] S. Cavalu, F. Banica, V. Simon, I. Akin, G. Goller, Surface modification of alumina/ zirconia ceramics upon different fluoride-based treatments, Int. J. Appl. Ceram. Technol. 11 (2014) 402-411.

[27] D. Sarkar, D. Mohapatra, S. Ray, S. Bhattacharyya, S. Adak, N. Mitra, Synthesis and characterization of sol-gel derived $\mathrm{ZrO} 2$ doped $\mathrm{Al} 2 \mathrm{O} 3$ nanopowder, Ceram. Int. 33 (2007) 1275-1282.

[28] J. Marchi, E.M. Amorim, D.R.R. Lazar, V. Ussui, A.H.A. Bressiani, P.F. Cesar, Physico-chemical characterization of zirconia-titania composites coated with an apatite layer for dental implants, Dent. Mater. 29 (2013) 954-962.

[29] S.Y. Lee, W.F. Regnault, J.M. Antonucci, D. Skrtic, Effect of particle size of an amorphous calcium phosphate filler on the mechanical strength and ion release of polymeric composites, J. Biomed. Mater. Res. B 80b (2007) 11-17.

[30] N.F. Amat, A. Muchtar, M.S. Amril, M.J. Ghazali, N. Yahaya, Effect of sintering temperature on the aging resistance and mechanical properties of monolithic zir conia, Journal of Materials Research and Technology 8 (2018) 1092-1101.

[31] E. Gregorová JH, W. Pabst, K. Kuneš, Heinrich, Aldinger, Slip casting of ATZ ceramics, Ceramic Materials and Components for Engines, 2017.

[32] F. Kern, R. Gadow, Alumina toughened zirconia from yttria coated powders, J. Eur. Ceram. Soc. 32 (2012) 3911-3918.

[33] M. Aivazi, M.H. Fathi, F. Nejatidanesh, V. Mortazavi, B. HashemiBeni, J.P. Matinlinna, et al., The evaluation of prepared microgroove pattern by femtosecond laser on alumina-zirconia nano-composite for endosseous dental implant application, Lasers Med. Sci. 31 (2016) 1837-1843.

[34] Y. Chen, B. He, J. Lee, N.A. Patankar, Anisotropy in the wetting of rough surfaces, J. Colloid Interface Sci. 281 (2005) 458-464.

[35] N.A. Patankar, On the modeling of hydrophobic contact angles on rough surfaces, Langmuir : the ACS journal of surfaces and colloids 19 (2003) 1249-1253.

[36] K. Anselme, M. Bigerelle, Role of materials surface topography on mammalian cell response, Int. Mater. Rev. 56 (2011) 243-266.

[37] M. Ermis, E. Antmen, V. Hasirci, Micro and Nanofabrication methods to control cellsubstrate interactions and cell behavior: a review from the tissue engineering perspective, Bioact Mater 3 (2018) 355-369.

[38] E. Martinez, E. Engel, J.A. Planell, J. Samitier, Effects of artificial micro- and nanostructured surfaces on cell behaviour, Ann. Anat. 191 (2009) 126-135.

[39] V. Hasirci, B.J. Pepe-Mooney, Understanding the cell behavior on nano-/micropatterned surfaces, Nanomedicine 7 (2012) 1375-1389.

[40] R.A. Delgado-Ruiz, J.L. Calvo-Guirado, P. Moreno, J. Guardia, G. Gomez-Moreno, J.E. Mate-Sanchez, et al., Femtosecond laser microstructuring of zirconia dental implants, J. Biomed. Mater. Res. B 96b (2011) 91-100.

[41] A.-M. Stanciuc, Q. Flamant, C.M. Sprecher, M. Alini, M. Anglada, M. Peroglio, Femtosecond laser multi-patterning of zirconia for screening of cell-surface interactions, J. Eur. Ceram. Soc. 38 (2018) 939-948. 